\title{
USE DESIGN PERFORMANCE BASED ON USE REQUIREMENTS
}

\author{
Mahdjoub, Morad (1); Bluntzer, Jean-Bernard (1); Bertin, Aymeric (2) \\ 1: Université de Technologie de Belfort-Montbéliard, France; 2: Alten Technologies
}

\begin{abstract}
Industrial companies today must operate in an increasingly competitive world and need to rethink their organization accordingly. First, industrial strategies concerning technical management need to change and develop. If we consider the specific management of the product design process, managers use indicators during the lifecycle of the product concerning quality, cost and lead-times. For example, some new indicators concerning performance metrics related to cooperation issues among the design team are set up. Secondly, managers increasingly need to integrate the user in the early phases of the design process. The main benefit of this approach is that it allows designers to innovate more rapidly and robustly. The aim of this paper is to introduce a new approach making it possible to calculate a performance indicator concerning use design. The new indicator will help management drive the design process through the integration of use in the product, helping to enhance the usability of the future product, and consequently improve innovation.
\end{abstract}

Keywords: Requirements, Use design, Performance indicator, Design for X (DfX), Collaborative design

Contact:

Mahdjoub, Morad

Université de Technologie de Belfort-Montbéliard, France

University of Bourgogne Franche-Comté, UTBM, ERCOS ELLIADD

France

morad.mahdjoub@utbm.fr

Cite this article: Mahdjoub, M., Bluntzer, J.-B., Bertin, A. (2019) 'Use Design Performance Based on Use Requirements', in Proceedings of the 22nd International Conference on Engineering Design (ICED19), Delft, The Netherlands, 5-8 August 2019. DOI:10.1017/dsi.2019.384 


\section{INTRODUCTION}

Against a backdrop of globalization and low growth, product design companies have to be competitive in order to survive and thus reduce time-to-market and costs while improving quality. To face the competition and accelerate the design process, teams must avoid processing sequentially. A sequential design process does not enable multidisciplinary teams to work at the same time on the product design, making the detection and resolution of issues long and expensive: the later an issue is detected, the more expensive it will be to correct in terms of time and costs. For this reason, design teams have to be cross-functional and work collaboratively, especially if the various teams are spread around the world. Collaborative work during design projects can be time-consuming and engage the success of the project. Collaborative design therefore involves the implementation of methods to manage design team performance.

Performance can be measured in a global way by focusing on economic data linked to the company. Performance can be also measured from the activity point of view based on production activities, design activities, etc. A performance indicator is defined as a variable indicating the effectiveness and/or the efficiency of a part or whole of the process or system against a given norm/target or plan (Lohman et al., 2004). Performance is expressed in relation to the attainment of a fixed objective, by comparison with the measurement. Performance indicators provide management with a tool to compare actual results with a preset target, and to measure the extent of any deviation (Fortuin, 1988). It also consists in providing information that helps the design staff or design team to focus their work on attaining an objective or a result. We can consider indicators focused on a process or management and others focused on the results of activities. In an engineering design context, (Škec et al., 2017) aspects of performance measurement are characterized by 3 dimensions. The indicators can be static or dynamic, tangible or intangible, and focus on an organization or a team/individual.

As an example, Anghel studied design iteration to propose a performance indicator (Anghel, 2007; Boudouh et al., 2006). Anghel measured iteration time and iteration type. He described iteration based on task repetition, the interaction between different design activities, the resolution of problems by a series of increasingly precise proposals, and negotiation between experts. Despite the high numbers of indicators and the level of detail, the proposed approach is complicated to carry out.

(Škec et al., 2017) proposed an approach that incorporates dynamic monitoring at the individual/team level of intangible measurements. Based on a highly exhaustive state of the art and several refinement phases, they proposed a set of 36 indicators for the individual level and 29 indicators for the team level. All of these indicators are associated with 3 specific data collection strategies (work sampling, survey and integration with corporate IT systems). The work results in intangible indicators with finegrain refinement measurements.

Concerning the product performance viewpoint, Lucero et al. propose performance metrics that can be classified as quantifiable quantities employed by engineers (Lucero et al., 2016) (Lucero et al., 2014). Using a functional basis (Hirtz et al., 2002), they associate critical flow (CF) and functions as a critical pair to identify relevant performance metrics.

Fleche et al. use quantitative and non-intrusive indicators during the management of collaborative design phases. They compute several indicators linked to the completeness of the CAD data in order to assess the performance of a collaborative design project (Fleche et al., 2017). Fleche makes the hypothesis that the completeness rate of the project can be measured by taking into account the modification rate of CAD data between two revisions. The less the CAD data have been modified, the more mature the CAD data. But the completeness rate measured by Fleche is dependent on the nonmodification rate of the CAD data. So the suggested indicator does not take into account the performance of the product concerning engineering metrics to be attained for example.

All of these works focus on various aspects of the performance metrics related to the product under development or the associated design activities. And they often focus on technical data that lie within the scope of design engineers. But product design projects involve multidisciplinary teams (industrial designers, mechanical engineers, ergonomists, UX designers, etc.) with different points of view of the product. The use of the product is one of them. Indeed, most of the time, a customer buys a product for its use function. As a cross-functional notion, use takes into account the user in the design process. Brangier defines use as the effective application of a product in a social context (Brangier and Barcenilla, 2003). Thus use can be considered as the interaction between the product, the user and the 
context (Al Khatib et al., 2014). Like the product, it is an artefact that can be designed and its design process consists in descriptive proposals satisfying requirements (Rasoulifar et al., 2007). But today, based on our knowledge of the literature, no indicators have been proposed to assess the performance of use design. In this paper we therefore propose to introduce a new exploratory study exposing a new approach making it possible to compute a performance indicator concerning use design. This indicator will allow the project team to identify during the project some new possibilities to innovate, discovering some new potential niches of innovation. For example, they can identify some new possibilities to improve the use of the actual product or improve directly the product himself. Therefore, it will be necessary to complete the existing metrics with a use design performance indicator which could help managers and designers take users into account in the design process. In the second section of this paper, we propose to describe the assumptions related to our new approach. The third section is dedicated to the description of our approach and the computation process of a new performance indicator. The final section proposes a conclusion and outlooks for further work.

\section{ASSUMPTIONS AND OBJECTIVES OF THE WORK}

Our work is based on a fifth assumption, which combines the first four. Our first assumption is: "use design performance can be measured in a quantitative way". It enables the computation of a measurable indicator. Our second assumption is: " use can be represented with a modelling language at each stage of the design process". This modelling language must enable a breakdown of the use into several parts, an easy and extensive understanding for all stakeholders of the design team and the computation of the indicator through a global approach. Our third assumption is: "To meet the needs of the design team, our approach must propose a use design performance indicator (UDPI) that can be used by any stakeholder in the project enabling them to (i) compute use design performance, and (ii) be informed about the performance status". Indeed, during a collaborative design process, use design involves different stakeholders from different disciplines. Our fourth assumption is: "Concerning use design, performance metrics are stored in the requirements". The computation of our indicator should involve target values that are defined in the requirements. These specific requirements, called in this paper Use Requirements (UR), must be extracted from the global requirements of the product.

Finally, a fifth assumption combines the first four: "Our approach links product/use modelling to the use requirements to compute a use design performance indicator".

The next section describes our approach concerning the computation of the use design performance indicator.

\section{THE USE DESIGN PERFORMANCE INDICATOR (UDPI)}

\subsection{Proposed approach}

The proposed approach is a combination of seven steps (cf. Figure 1).

The first step concerns the requirements definition. At the beginning of a product design project, members of the project team have to draft the requirements. Requirements stem from the whole lifecycle of the product. For instance, they can involve technical, manufacturing and use issues.

The second and the third steps concern the product/use definition and modelling, which are carried out by the various stakeholders in a collaborative way. Concerning use, we propose to choose a specific modelling language to answer our second assumption. It is based on the International Classification of Functioning, Disability and Health (ICF) ("ICF Browser," n.d.) (World Health Organization, 2001). The ICF was established by the World Health Organization and provides a standardized lexicon and taxonomy for the description of health and health-related states. (Sangelkar et al., 2012) proposes user activity modelling based on this lexicon. It is a suitable way to describe user activities related to consumer products (McAdams and Kostovich, 2011) (Sangelkar, 2011). User activities can be modelled with repeatability and common understanding of all design team members.

Similarly, product definition and modelling are carried out with conventional, well-known activities and tools.

The fourth step performs a selection of Use Requirements (UR) in order to prepare the computation of the UDPI. The computation involves combining the UR and the product/use definition. This step and the definition of UR are detailed in the next section. 
The computation provides the UPDI and other information that can be monitored in the sixth step by the design team members.

In the last step, a modifications report is generated. After each computation, this allows the indicator to be studied and generates a modifications report dedicated to the product and/or the use definition and sometimes the requirements definition. Until the end of the design project, regular updates corresponding to iterations can be made and saved as new versions.

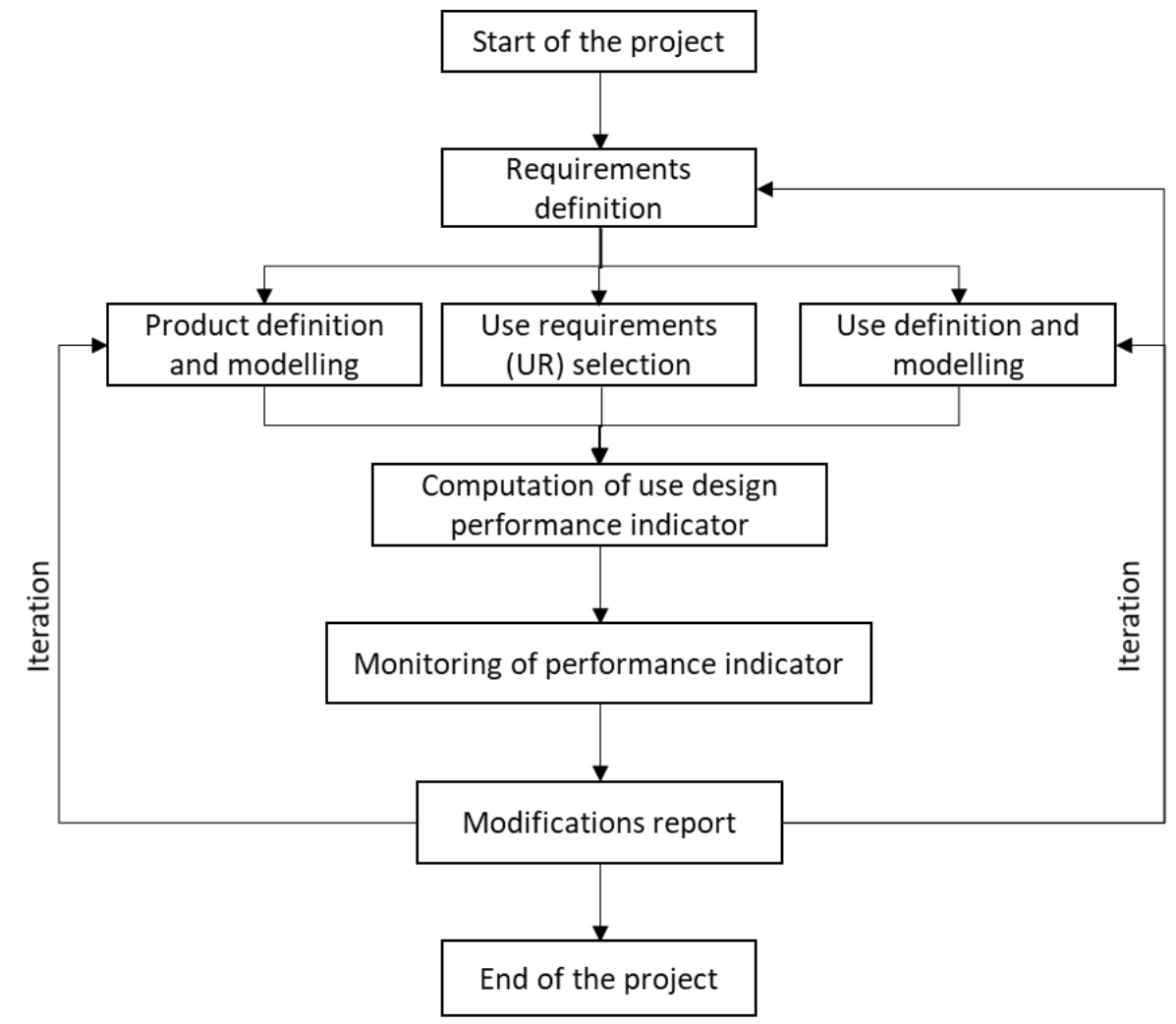

Figure 1. Flowchart for the definition of Use performance

\subsection{Calculating the use design performance indicator (UDPI)}

Figure 2 illustrates the steps involved in calculating the Use design performance indicator. The calculation is explained in the following sections. The calculation step is illustrated with a project realised by French students in mechanical and ergonomics engineering. The project involves the design of a smartphone projector scheduled to be made by the user with 3D printing technology.

In order to calculate our approach, we used Visual Basic applied to Microsoft Excel, because it enables access to a large panel of users and can be tested at minimum cost. 


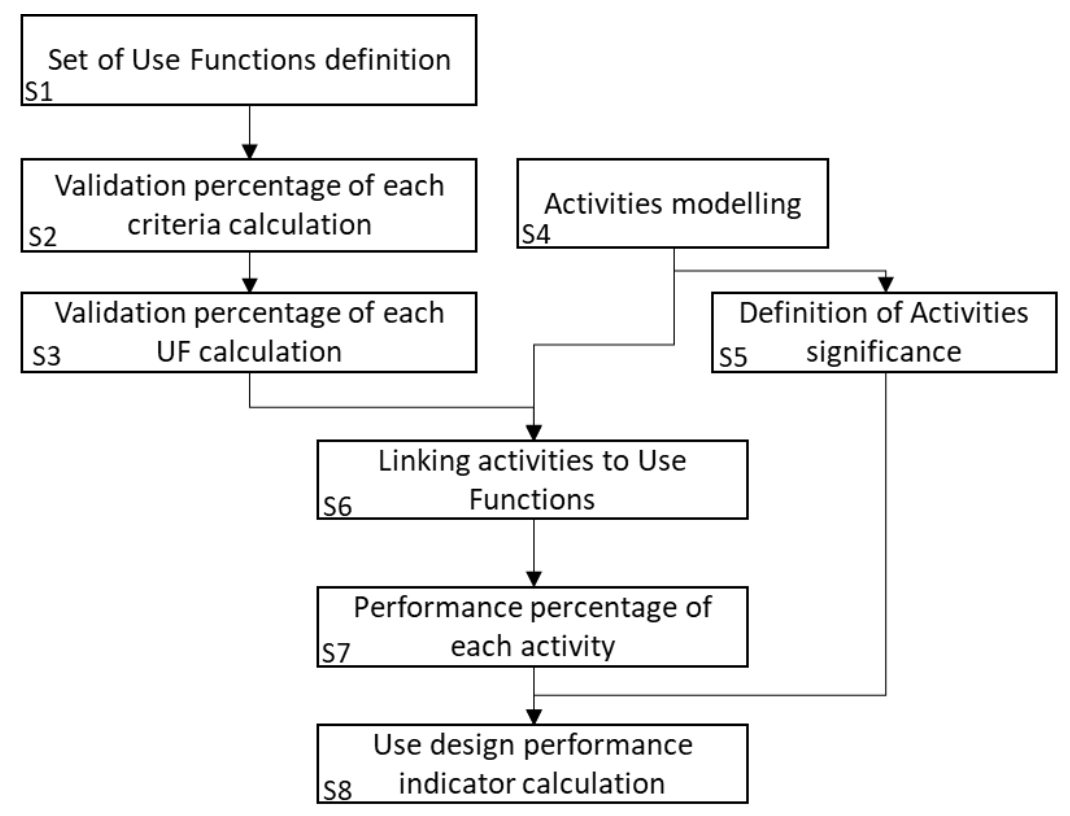

Figure 2. Computation steps for UPDI $(S X=S t e p X)$

\subsubsection{Validation percentage of the UR}

Concerning the use design, we assume that performance metrics are stored in the requirements. The first step of the computation involves calculating the validation percentage of the UR. UR is defined as a set of Use Function (UF) associated with a criterion and a target value (Step 1, Figure 2). Most of the time the values can be tangible measurements, grades, descriptors or any number which can quantify the criteria. In this way, the validation percentage of the UR is obtained by calculating the validation percentages of all the UFs.

Table 1. A set of Use Functions defined during the student project

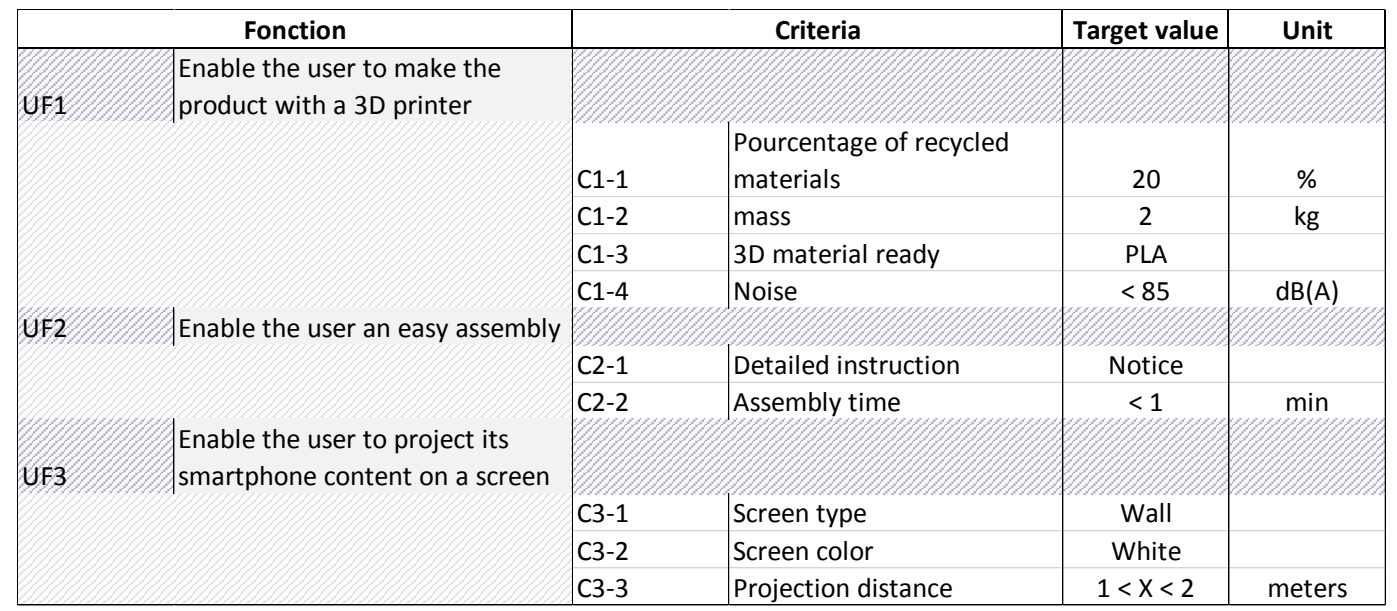

Table 1 shows an illustration of the student project. It is a part of all the requirements obtained during their project. For instance, UF3 is "Enable the user to project its smartphone content on a screen". For this function, some instances of the associated criteria (Ci-j) are "C4-1 Screen type", "C4-2 Screen color" and "C4-3 Projection distance". As shown in Table 1, the associated target value can be a tangible measurement (projection distance), or a descriptor (screen color and screen type).

In step 2 (Figure 2), a validation percentage is calculated for each criterion (\% ValCi). It represents the capability of the product to attain the target value. The percentage is defined upon the difference between the target value and the value obtained with the product definition. For a criterion associated with a target value defined by a descriptor, the percentage can be forced with a value determined by the design team member. 
In step 3 (figure 2), the validation percentage of each UF (\%VALUF) is calculated by linking the average of \% ValCi to the function (Equation 1).

$$
\% V A L_{U F}=\frac{\sum_{1}^{n} \% V A L_{C i}}{n}
$$

Table 2 shows an extract of the calculation for 3 UF. The design team member can complete the table with the value obtained for each criterion and the validation percentage is automatically calculated. The obtained value can be defined during use tests upon physical or virtual prototypes. For example, C1-1 has a score of $100 \%$ because the obtained value is equal to the target value.

The design team member can force a value for a criterion thanks to the column "Forcing value?" (Table 2). This possibility is used when the project progress does not permit a test on the criterion. For instance, it is often the case during the beginning of the project when prototypes are not available. When "Yes" is chosen, a value between 0 and 100 in the column "Forced value" can be set. For instance, \%VAL C2-2 is forced with $20 \%$.

Table 2 also shows that UF3 has a score of 72\%. It corresponds to the average of C3-1, C3-2 and C33. For the same reason, forcing the validation percentage of UF is also permitted for the user.

Table 2. Calculation of \%VALUF

\begin{tabular}{|c|c|c|c|c|c|c|c|c|c|}
\hline & Use Function & & Criteria & Obtained Value & Target value & Unit & $\begin{array}{l}\text { Forcing } \\
\text { value? }\end{array}$ & Forced value & $\begin{array}{l}\text { Validation } \\
\text { percentage }\end{array}$ \\
\hline \multirow[t]{5}{*}{$0 F 1$} & $\begin{array}{l}\text { Enable the user to make } \\
\text { the product with a 3D } \\
\text { printer }\end{array}$ & & & & & & No & & $100 \%$ \\
\hline & & C1-1 & $\begin{array}{l}\text { Pourcentage of recycled } \\
\text { materials }\end{array}$ & 20 & 20 & $\%$ & No & & $100 \%$ \\
\hline & & C1-2 & Mass & 0,893 & $<2$ & $\mathrm{~kg}$ & Yes & $100 \%$ & $100 \%$ \\
\hline & & C1-3 & 3D material ready & & PLA & & Yes & $100 \%$ & $100 \%$ \\
\hline & & C1-4 & Noise & 80 & $<85$ & $d B(A)$ & Yes & $100 \%$ & $100 \%$ \\
\hline \multirow[t]{3}{*}{$0 \times 2$} & $\begin{array}{l}\text { Enable the user an easy } \\
\text { assembly }\end{array}$ & & & & & & No & & $60 \%$ \\
\hline & & C2-1 & Detailed instruction & / & Notice & & Yes & $100 \%$ & $100 \%$ \\
\hline & & $C 2-2$ & Assembly time & 5 & 1 & $\min$ & Yes & $20 \%$ & $20 \%$ \\
\hline \multirow[t]{4}{*}{ UF3 } & $\begin{array}{l}\text { Enable the user to project } \\
\text { its smartphone content on } \\
\text { a screen }\end{array}$ & & & & & & No & & $72 \%$ \\
\hline & & C3-1 & Screen type & I & Wall & & Yes & $75 \%$ & $75 \%$ \\
\hline & & C3-2 & Screen color & / & White & & Yes & $80 \%$ & $80 \%$ \\
\hline & & C3-3 & Projection distance & / & $1<x<2$ & & Yes & $60 \%$ & $60 \%$ \\
\hline
\end{tabular}

\subsubsection{Definition of activity significance}

Step 4 (Figure 2) consists in Use modelling based on the ICF lexicon (World Health Organization, 2001). Use is defined on the basis of activities and tasks. Activities describe the main steps of the product use achievement. Activities are defined by project team based on use observations of an existing product or assumptions if a real situation is not reachable. Each activity is divided as a set of tasks. Tasks are defined thanks to ICF lexicon.

Table 3 shows an excerpt from of the entire Use modelling for the smartphone project. For instance, Activity 1 is "Remove the stand and separate the pattern in order to position the smartphone". For each activity, the design team member can fill in some information: precedence, Task number, Task name (from ICF lexicon), and ICF code.

Step 5 (Figure 2) consists in calculating the significance of each activity. The significance of each activity is compared in pairs using a comparison matrix. A four-level scale (from 0 to 3 ) is used to fill in the matrix. 0 means that the two activities are equal, 1 means "slightly more important than the other", 2 means "more important than the other" and 3 means "much more important than the other". The score is subjective and is given by only one team member or in a collaborative way. Based on the scores, a relative significance is calculated for each activity.

Table 3 shows an excerpt from the use modelling with ICF lexicon for the smartphone project. For instance Activity 1 "Remove the stand and separate the pattern in order to position the smartphone" is detailed with 3 tasks based on the ICF lexicon. Each Task name is associated with its ICF code: TH1-1 "Picking up" (d4400 ICF code), TH1-2 "Grasping" (d4401 ICF code), TH1-3 "Pulling" (d4450 ICF code) and TH1-4 "Manipulating" (d4402 ICF code). 
Table 3. Excerpt from use modelling with ICF lexicon

\begin{tabular}{|c|c|c|c|c|}
\hline Activity 0 & \multicolumn{4}{|l|}{ Product assembly by user } \\
\hline \multicolumn{5}{|l|}{ Preceding(s) } \\
\hline Task number & Tho-1 & Tho-2 & & \\
\hline Task name & $\begin{array}{l}\text { Undertaking a complex } \\
\text { task }\end{array}$ & $\begin{array}{l}\text { Visual } \\
\text { perception }\end{array}$ & & \\
\hline \multicolumn{5}{|l|}{ ICF code } \\
\hline Activity 1 & \multicolumn{4}{|c|}{$\begin{array}{l}\text { Remove the stand and separate the pattern in order to position the } \\
\text { smartphone }\end{array}$} \\
\hline \multicolumn{5}{|l|}{ Preceding(s) } \\
\hline Task number & Th1-1 & Th1 2 & Th1 -3 & Th1-4 \\
\hline Task name & Picking up & Grasping & Pulling & Manipulating \\
\hline ICF code & $\mathrm{d} 4400$ & $\mathrm{~d} 4401$ & $\mathrm{~d} 4450$ & $\mathrm{~d} 4402$ \\
\hline Activity 2 & \multicolumn{4}{|c|}{$\begin{array}{l}\text { Connect the stand and the pattern and place it in the smartphone } \\
\text { projector }\end{array}$} \\
\hline \multicolumn{5}{|l|}{ Preceding(s) } \\
\hline Task number & Th2 $2-1$ & Th2 22 & & \\
\hline Task name & Manipulating & Pushing & & \\
\hline ICF code & $\mathrm{d} 4402$ & d4451 & & \\
\hline
\end{tabular}

\subsubsection{Activity performance and UDPI computation}

Once the UF percentage validation and activity significances have been calculated, design team members have to link the activities with the UF (Step 6, Figure 2). The links between activities and UF is subjective and have to be reported following the table 4 .

Table 4. Links between activities and UF

\begin{tabular}{|c|c|}
\hline Value & Link \\
\hline 0 & Not linked \\
\hline 1 & Linked \\
\hline 2 & Very linked \\
\hline
\end{tabular}

To complete Step 7 (Figure 2), a performance percentage for each activity is calculated using a weighted average (Equation 2). For each activity, the sum of each link value multiplied by the corresponding \%VALUF is divided by the sum of all the link values of the activity.

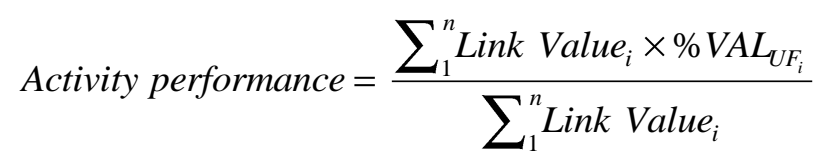

Table 5 shows the whole data for the UDPI calculation of the student project. It shows the links between all of the UFs and all of the activities. For instance, the performance percentage of "activity 0 " is equal to $79.6 \%$.

Table 5. Data for UDPI computation

\begin{tabular}{|c|c|c|c|c|c|c|c|c|c|c|c|c|c|c|c|c|}
\hline & Use Functions & UF1 & UF3 & UF4 & UF5 & UF6 & UF11 & UF12 & UF13 & UF15 & UF16 & UF17 & UF 18 & I & & \\
\hline & $\% \mathrm{VAL}_{\mathrm{UF}} \rightarrow$ & $100 \%$ & $60 \%$ & $72 \%$ & $76 \%$ & $100 \%$ & $87 \%$ & $63 \%$ & $48 \%$ & $77 \%$ & $100 \%$ & $100 \%$ & $80 \%$ & I & & \\
\hline Activities & $\begin{array}{c}\text { Activity } \\
\text { Significance } \downarrow\end{array}$ & & & & & & & & & & & & I & $\begin{array}{l}\text { I Activity } \\
\text { performan } \\
\text { ce }\end{array}$ & \begin{tabular}{|c|} 
Activity \\
Relative \\
weight
\end{tabular} & UDPI \\
\hline Activity 0 & $21 \%$ & 2 & 1 & 1 & 0 & 0 & 2 & 1 & 1 & 0 & 1 & 0 & 0 & $79,6 \%$ & 0,190 & \\
\hline Activity 1 & $18 \%$ & 1 & 2 & 2 & 0 & 1 & 1 & 1 & 1 & 0 & 1 & 0 & 0 & $76,1 \%$ & 0,183 & \\
\hline Activity 2 & $12 \%$ & 1 & 2 & 1 & 1 & 2 & 1 & 1 & 1 & 1 & 0 & 1 & 0 & $78,5 \%$ & 0,150 & \\
\hline Activity 3 & $11 \%$ & 1 & 2 & 1 & 0 & 1 & 1 & 1 & 1 & 1 & 0 & 1 & 0 & $76,6 \%$ & 0,115 & \\
\hline Activity 4 & $4 \%$ & 0 & 1 & 2 & 0 & 0 & 0 & 1 & 1 & 2 & 2 & 1 & 0 & $76,8 \%$ & 0,038 & \\
\hline Activity 5 & $9 \%$ & 0 & 1 & 2 & 0 & 1 & 0 & 2 & 2 & 2 & 1 & 0 & 0 & $70,8 \%$ & 0,095 & $76 \%$ \\
\hline Activity 6 & $13 \%$ & 0 & 1 & 2 & 0 & 1 & 0 & 2 & 2 & 1 & 1 & 1 & 0 & $72,9 \%$ & 0,148 & \\
\hline Activity 7 & $8 \%$ & 0 & 1 & 1 & 1 & 1 & 0 & 1 & 1 & 1 & 1 & 0 & 0 & $74,4 \%$ & 0,062 & \\
\hline Activity 8 & $3 \%$ & 0 & 1 & 0 & 0 & 1 & 0 & 1 & 1 & 1 & 0 & 0 & 0 & $169,5 \%$ & 0,014 & \\
\hline Activity 9 & $1 \%$ & 0 & 0 & 0 & 1 & 0 & 0 & 1 & 1 & 1 & 0 & 0 & 0 & $65,9 \%$ & 0,004 & \\
\hline Activity 10 & $0 \%$ & 0 & 0 & 0 & 0 & 0 & 0 & 1 & 1 & 2 & 2 & 0 & 0 & $77,4 \%$ & 0,000 & \\
\hline
\end{tabular}

The relative weight of each activity (linking activity significance and the associated link values) is calculated. Equation 3 shows the detailed calculation. For each activity, it involves calculating the sum 
of each link value multiplied by the corresponding activity significance divided by the sum of all link values multiplied by the corresponding activity significance.

$$
\text { Activity relative weight }=\frac{\sum(\text { Link value } \times \text { activity significance })}{\sum \sum(\text { Link value } \times \text { activity significance })}
$$

For instance the relative weight of "Activity 0" is equal to 0.19 (Table 5).

Finally (Step 8, Figure 2), the UDPI is calculated as the sum of the products between the performance and relative weight of each activity (Equation 4).

$$
U D P I=\sum \text { Activity performance } \times \text { Activity relative weight }
$$

For instance, at this step of the smartphone projector project, the UPDI is equal to $76 \%$.

The next section describes the project reports and developments that can be obtained using the calculation.

\subsection{Indicator monitoring and modification report}

\subsubsection{Indicator monitoring}

The UDPI depends on several data: the set of UF and the associated criteria, the validation percentage of criteria (\%VALC), the validation percentage of the UF (\%VALUF), the activity significance and activity performance percentages.

The UDPI calculation concerns the condition of the use design in the project at a moment in time. To enable design team members to follow its development, it has to be reviewed regularly in the design process using versioning. We therefore proposed that design team members monitor the number of criteria, activities, tasks and UDPI percentages. Versioning needs to be performed frequently, depending on the project, for example on a daily, weekly or monthly basis.

Figure 3, as an example of the development in the UDPI during the smartphone projector design project, shows five versions. It shows that the UDPI is consistent throughout these five iterations. From version 1 to version 3, it increases from $76 \%$ to $80 \%$ with a consistent number of criteria, activity and tasks. Then, from version 3 to version 5, the UDPI decreases from $80 \%$ to $79 \%$. This change can help design team members understand and manage the project from use design point of view.

The next section explains how designers can use these data to propose modification reports.

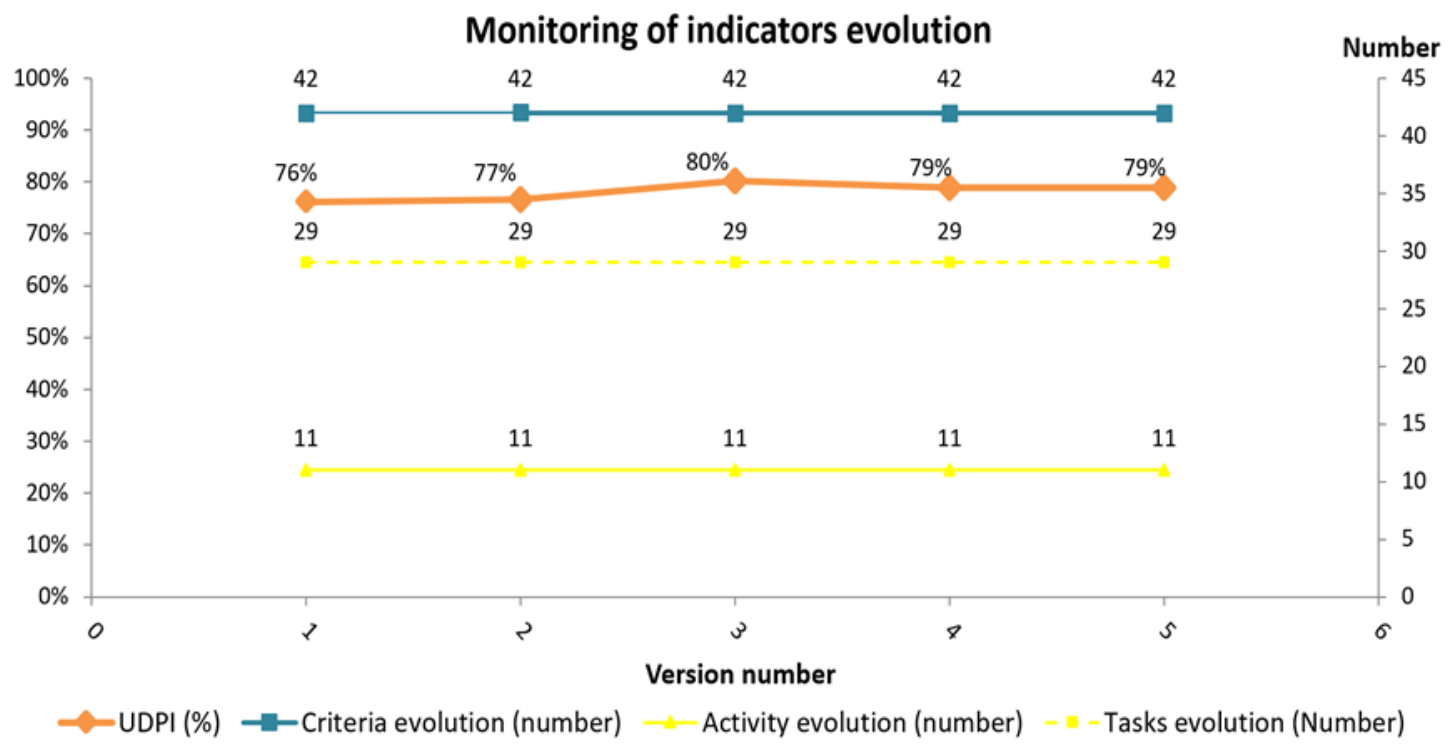

Figure 3. Change in the UDPI during the smartphone projector design project 


\subsubsection{Modification report}

Faced with a low UDPI value, design team members can analyse Table 5 to detect which activity(ies) have weak performance (Equation 4). If several activities are concerned, priority ranking can be defined using the activity significance.

From this(ese) activity(ies), the designers can retrieve the associated UF. Indeed, "Activity performance" is calculated with \%VALUF (Equation 2). So the designers can detect which UF has a weak \%VALUF. Then, in Table 2, they can find which criteria are the cause of the weak value. Using these criteria, design team members can define modifications or recommendations that can be applied either to the product definition or to the use definition (iteration in Figure 1). We assume that both of them can play a role in the improvement of the use design performance.

As an illustration, Activity 9 (Table 5) has a performance value of $65.9 \%$. The designers can rapidly see in the "activity significance" column that it has a significance of $1 \%$. This means that it may not be a priority in the use design process. If the designers want to investigate further, they can detect that UF12 and UF13, with respectively $63 \%$ and $48 \%$ of \%VALUF, are problematic. Finally, by analysing $\%$ VALC they can obtain the associated criteria that must be improved.

In order to have feedback about use design and product design, Table 5 can be analysed by two ways. First, it can be used to detect inconsistencies in the link column associated with a UF. If the link sum is equal to zero it means that in fact this UF is not really associated with use aspects. Secondly, in Table 5 , we can also detect if the activity has a significance of $0 \%$. It can be an indication of an incorrect use definition or consideration of the activity.

As an illustration, table 5 shows that the value of UF18 in its column is only zero, indicating that this function may not be linked to the use design. Indeed, UF18 was defined by the students as "To generate energy". Again, Activity 10 has a significance of $0 \%$. This activity was defined as "To Store the smartphone projector". In this case, the design team member must investigate this point and perhaps reassess the significance of the activity.

\section{CONCLUSION}

In this paper, we have proposed a new approach in order to calculate a use design performance indicator (UDPI) used during collaborative projects. It is based upon data from requirements and use modelling. The approach is supported by a calculation step which is well defined and open for an easy reuse by the community, being based upon a free and universal modelling language (ICF lexicon). Our calculation method is also flexible enough to be well suited for the early steps of the product design process. This means designers can evaluate UF or criteria without any calculation. They can force validation percentage from their personal experience. In addition, the easy method of calculation allows the designers to monitor the changes in the UDPI and other indicators throughout the project, and use iteration of the product. The designers can also easily retrieve indications with which to propose modifications and recommendations concerning either the product or its use.

Nevertheless, our approach has not been implemented on real design projects that could have spotlighted eventual failures and difficulties. The use of our approach in an industrial context will allow us to entire validate and evaluate the new metric UDPI. Although it has been used during student projects, the point of view of an industrialist is important perspective for this work. It would also allow us to carry out a survey of the relevance of our approach. Another perspective concerns the Use Requirement. Indeed, we think that we can complete our approach the implementing notion of User Experience. It could add some functions or objectives that we do not frequently find in requirements. The representation of usability, accessibility, emotionality and persuasion objectives could contribute genuine added value to the UPDI.

\section{REFERENCES}

Anghel, D.-C. (2007), Contribution à l'analyse des itérations dans le processus de conception : proposition d'indicateurs d'évaluation de performances (thesis), Besançon.

Boudouh, T., Anghel, D.-C. and Garro, O. (2006), "Design Iterations in a Geographically Distributed Design Process", In: H.A. ElMaraghy and W.H. ElMaraghy, (Ed.), Advances in Design, Springer Series in 
Advanced Manufacturing, Springer London, London, pp. 377-385. https://doi.org/10.1007/1-84628-210$1 \_31$.

Brangier, E. and Barcenilla, J. (2003), Concevoir un produit facile à utiliser, Editions d'organisation, Paris.

Fleche, D., Bluntzer, J.-B., Al Khatib, A., Mahdjoub, M. and Sagot, J.-C. (2017), “Collaborative project: Evolution of computer-aided design data completeness as management information", Concurrent Engineering, Vol. 25, pp. 212-228. https://doi.org/10.1177/1063293X17694416.

Fortuin, L. (1988), "Performance indicators - Why, where and how?", European Journal of Operational Research, Vol. 34, pp. 1-9. https://doi.org/10.1016/0377-2217(88)90449-3.

Hirtz, J., Stone, R.B., McAdams, D.A., Szykman, S. and Wood, K.L. (2002), “A functional basis for engineering design: Reconciling and evolving previous efforts”, Res Eng Design, Vol. 13, pp. 65-82. https://doi.org/10.1007/s00163-001-0008-3.

ICF Browser [WWW Document], (n.d.), URL http://apps.who.int/classifications/icfbrowser/ (accessed 11.29.18).

Al Khatib, A., Mahdjoub, M., Bluntzer, J.-B. and Sagot, J.-C. (2014), "Management of intermediary objects in the context of multidisciplinary convergence: Towards CBR", TMCE International Symposium, Hungaria, Budapest, pp. 12.

Lohman, C., Fortuin, L. and Wouters, M. (2004), "Designing a performance measurement system: A case study”, Eur J Oper Res 2004, pp. 267-286. https://doi.org/10.1016/S0377-2217(02)00918-9.

Lucero, B., Linsey, J. and Turner, C.J. (2016), "Frameworks for organising design performance metrics", Journal of Engineering Design, Vol. 27, pp. 175-204. https://doi.org/10.1080/09544828.2015.1135235.

Lucero, B., Viswanathan, V.K., Linsey, J.S. and Turner, C.J. (2014), "Identifying Critical Functions for Use Across Engineering Design Domains”, J. Mech. Des, Vol. 136, pp. 121101-11. https://doi.org/10.1115/1.4028280.

McAdams, D.A. and Kostovich, V. (2011), “A framework and representation for universal product design”, International Journal of Design, Vol. 5.

Rasoulifar, R., Thomann, G., Caelen, J. and Villeneuve, F. (2007), "Proposal of a New Design Methodology in the Surgical Domain”, ICED'07, International Conference On Engineering Design, Paris, France, pp. 12.

Sangelkar, S., Cowen, N. and McAdams, D. (2012), "User activity - product function association based design rules for universal products”, Design Studies, Vol. 33, pp. 85-110. https://doi.org/10.1016/j.destud.2011.06.002.

Sangelkar, S.C. (2011), Adapting ADA Architectural Design Knowledge to Product Design: Groundwork for a Function Based Approach (Thesis).

Škec, S., Cash, P. and Štorga, M. (2017), “A dynamic approach to real-time performance measurement in design projects”, Journal of Engineering Design, Vol. 28, pp. 255-286. https://doi.org/10.1080/09544828.2017.1303665.

World Health Organization (2001), International classification of functioning, disability and health: ICF, World Health Organization, Geneva. 